\title{
Effect of Obesity on Component Alignment in Total Knee Arthroplasty
}

\author{
Connor Ojard, MD, ${ }^{1,2}$ Alexander Habashy, MD, ${ }^{1,2}$ Mark Meyer, MD, ${ }^{1,2}$ George Chimento, MD, ${ }^{1,2}$ John L. Ochsner, MD ${ }^{1,2}$ \\ ${ }^{1}$ Department of Orthopedic Surgery, Ochsner Clinic Foundation, New Orleans, LA ${ }^{2}$ The University of Queensland School of Medicine, \\ Ochsner Clinical School, New Orleans, LA
}

Background: Obesity is routinely cited as a negative predictive factor for outcomes after total knee arthroplasty (TKA), but the direct mechanism responsible for this relationship has not been described. One possible explanation is a propensity for component malalignment in obese patients that is attributable to difficulty with surgical exposure.

Methods: This study evaluated the effect of obesity on TKA component alignment in 251 primary TKAs during a 12-month period at a single center in 2009. Postoperative component alignment was retrospectively measured and compared between patients defined as obese (body mass index $[\mathrm{BMl}] \geq 30 \mathrm{~kg} / \mathrm{m}^{2}$ ) and patients defined as nonobese $\left(\mathrm{BMI}<30 \mathrm{~kg} / \mathrm{m}^{2}\right.$ ). Alignment was determined by measuring the coronal tibiofemoral angle, coronal femoral component angle, coronal tibial component angle, sagittal femoral component angle, and sagittal tibial component angle in all of the study patients.

Results: Statistical analysis failed to demonstrate a statistically significant relationship between obesity and component alignment in any of the measured parameters.

Conclusion: The results of this study support that obesity does not negatively affect TKA component alignment; another factor must be associated with the worse outcomes in obese patients undergoing TKA.

Keywords: Body mass index, obesity, total knee arthroplasty

Address correspondence to Mark Meyer, MD, Department of Orthopedic Surgery, Ochsner Clinic Foundation, 1514 Jefferson Hwy., New Orleans, LA 70121.Tel: (504) 842-3970. Email: msmeyer@ochsner.org

\section{INTRODUCTION}

Total knee arthroplasty (TKA) is widely regarded as one of the most successful orthopedic surgical procedures. ${ }^{1,2}$ The orthopedic literature's commonly quoted 15-year TKA survival rate of approximately $90 \%{ }^{1-4}$ is dependent upon patientrelated factors, ${ }^{5,6}$ prosthesis-related factors, ${ }^{7}$ and surgical technique-related factors. ${ }^{8}$ Although the morbidity and mortality associated with the patient-related factor of obesity are well recognized in the medical literature ${ }^{9-11}$ the current orthopedic literature exploring the specific nature of this relationship is inconclusive, with some studies finding little difference in outcomes and others demonstrating inferior results. ${ }^{3,4,12-21}$

An important surgical technique-related factor is femoral and tibial component alignment. ${ }^{22}$ Malpositioning of either component has been associated with the failure of TKAs secondary to aseptic loosening, instability, polyethylene wear, and dislocation of the patella. ${ }^{22-25}$ The aim of this study was to evaluate the relationship between the patientrelated factor of obesity and the surgical technique-related factor of TKA component alignment.

\section{METHODS}

After obtaining institutional review board approval, retrospective data were collected on 320 consecutive primary cemented posterior cruciate-substituting total knee replacements (equipment providers Zimmer Biomet, Exactech Inc., and Stryker Corporation) performed by 3 surgeons (M.M., G.C., and J.L.O.) during a 12-month period beginning in January 2009. All surgeons used a standard surgical technique for TKA, including medial parapatellar arthrotomy and soft tissue releases as indicated. Intramedullary femoral cutting guides with posterior referencing and extramedullary tibial cutting guides were used to verify alignment intraoperatively. All components after trial fitting were secured with bone cement in a standard fashion. During the trial period, none of the surgeons made any significant changes to his surgical techniques. Standard postoperative radiographs of the included patients were appraised by a postgraduate year 5 orthopedic surgery resident who was blinded to the patients' body mass index (BMI). Five commonly accepted radiographic measurements were obtained: the coronal tibiofemoral angle (CTFA), the coronal femoral component angle (CFCA), the coronal tibial component angle (CTCA), the sagittal femoral component angle (SFCA), and the sagittal tibial component angle (STCA) (Figures 1 and 2).

BMI was calculated for each patient using a standardized formula $\left(\mathrm{kg} / \mathrm{m}^{2}\right)$ based on data entered into the medical 


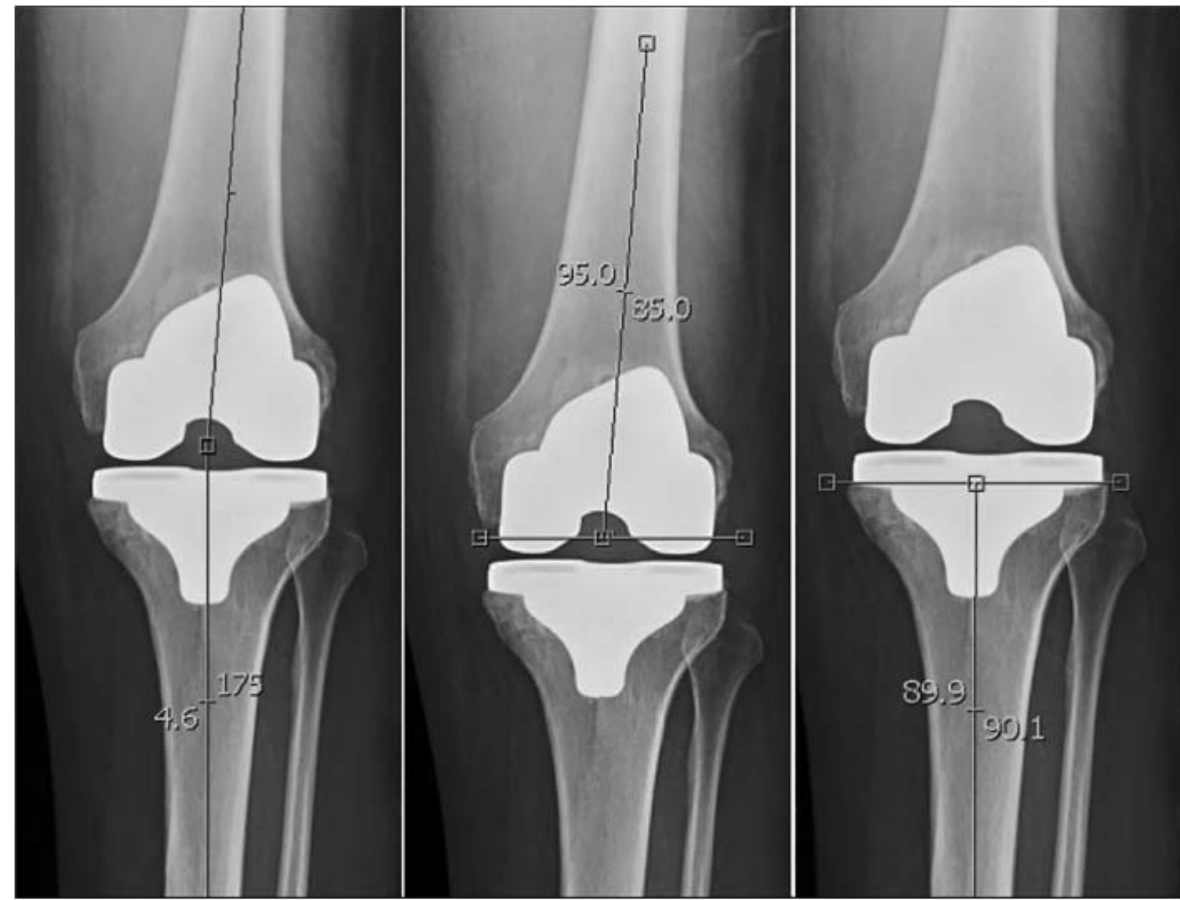

Figure 1. Radiographic determination of coronal alignment in total knee arthroplasty. Coronal tibiofemoral (left), femoral (middle), and tibial (right) measurements are shown.

record at the most recent preoperative assessment, which for most patients was the morning of surgery. The World Health Organization has defined obesity as a BMI $\geq 30 \mathrm{~kg} / \mathrm{m}^{2}$. For purposes of the study, patients were categorized as either obese (BMI $\geq 30 \mathrm{~kg} / \mathrm{m}^{2}$ ) or nonobese (BMI $<30 \mathrm{~kg} / \mathrm{m}^{2}$ ).

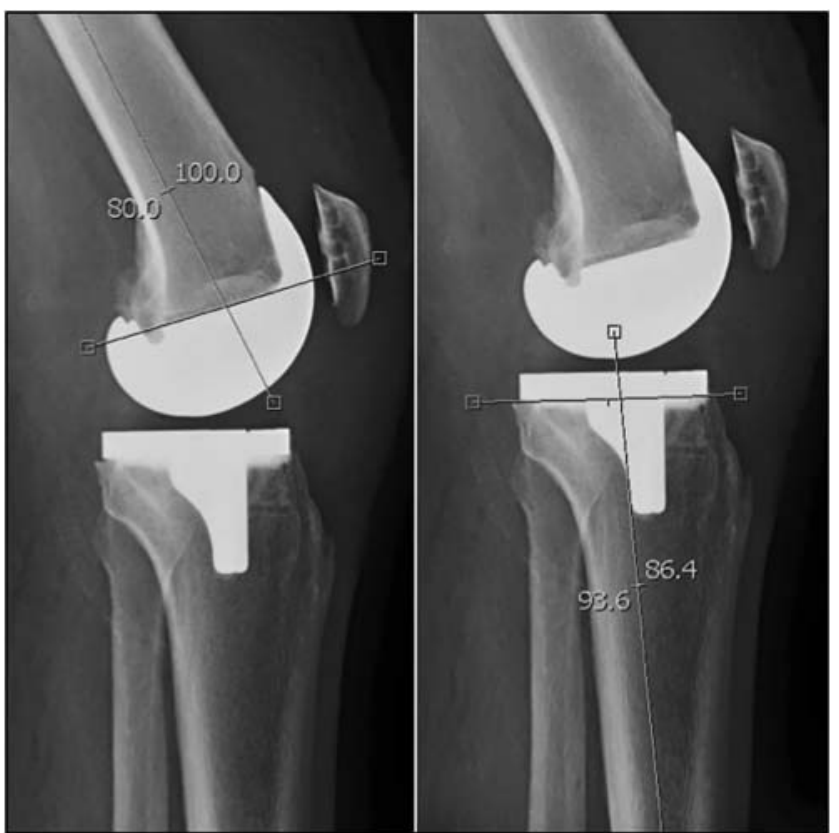

Figure 2. Radiographic determination of sagittal alignment in total knee arthroplasty. Sagittal femoral (left) and tibial (right) measurements are shown.
Chi-square analysis was used to investigate potential group differences for the categorical variables of sex and involved lower extremity between the obese and nonobese groups. Independent $t$ tests were used to evaluate potential differences for the continuous variables of age, CTFA, CFCA, CTCA, SFCA, and STCA. Statistical significance was set at $P<0.05$, and the statistical tests were performed using online GraphPad Software.

\section{RESULTS}

Two hundred and fifty-one knees in 153 patients had adequate postoperative radiographs to allow inclusion in the study. Of these, 49 patients underwent bilateral TKAs. Based on BMI values, 149 knees were included in the obese group and 102 knees were included in the nonobese group. Demographic characteristics of the two groups are shown in Table 1. The differences in sex and laterality between the obese and nonobese groups were not significant $(P=0.2943$ and $P=0.7013$, respectively). The mean ages in the 2 groups were 63.9 years in the obese group and 71.4 in the nonobese group. The difference in ages was statistically significant $(P<0.001)$.

Table 2 shows the component alignment measurements in the 2 groups. The mean CTFA was $184.1^{\circ}$ for the obese group and $184.7^{\circ}$ for the nonobese group. The mean CFCA was $94.6^{\circ}$ for the obese group and $95.9^{\circ}$ for the nonobese group. The mean CTCA was $89.7^{\circ}$ for the obese group and $89.8^{\circ}$ for the nonobese group. The differences in all 3 coronal alignment measurements were not statistically significant ( $P=0.0556, P=0.2246$, and $P=0.7264$, respectively).

The mean SFCA was $84.7^{\circ}$ for the obese group and $85.1^{\circ}$ for the nonobese group. The mean STCA was $86.6^{\circ}$ for the obese group and $86.5^{\circ}$ for the nonobese group. The 
Table 1. Baseline Demographic Data

\begin{tabular}{lccc}
\hline Variable & $\begin{array}{c}\text { All Patients } \\
\mathbf{n = 2 5 1}\end{array}$ & $\begin{array}{c}\text { Obese Group } \\
\mathbf{n = 1 4 9}\end{array}$ & $\begin{array}{c}\text { Nonobese Group } \\
\mathbf{n = 1 0 2}\end{array}$ \\
\hline $\begin{array}{l}\text { Sex } \\
\quad \text { Male }\end{array}$ & $96(38 \%)$ & $53(36 \%)$ & 0.2943 \\
$\quad$ Female & $155(62 \%)$ & $96(64 \%)$ & $43(42 \%)$ \\
Laterality & & $59(58 \%)$ & 0.7013 \\
$\quad$ Right knee & $117(47 \%)$ & $71(48 \%)$ & $46(45 \%)$ \\
$\quad$ Left knee & $134(53 \%)$ & $78(52 \%)$ & $56(55 \%)$ \\
Mean age, years (range) & $66.9(40-88)$ & $63.9(40-85)$ & $71.4(52-88)$ \\
Mean body mass index, $\mathrm{kg} / \mathrm{m}^{2}$ (range) & $32.7(20.2-53.0)$ & $37.0(30.1-53.0)$ & $26.5(20.2-29.9)$ \\
\hline
\end{tabular}

Table 2. Component Alignment Measurements by Group

\begin{tabular}{lccc}
\hline Radiographic Measurement & $\begin{array}{c}\text { Obese Group } \\
\mathbf{n}=\mathbf{1 4 9}\end{array}$ & $\begin{array}{c}\text { Nonobese Group } \\
\mathbf{n}=102\end{array}$ & \multicolumn{1}{c}{$\boldsymbol{P}$ Value } \\
\hline Coronal tibiofemoral angle & $184.1^{\circ}\left(180^{\circ}\right.$ to $\left.191.0^{\circ}\right)$ & $184.7^{\circ}\left(178.0^{\circ}\right.$ to $\left.191.0^{\circ}\right)$ & 0.0556 \\
Coronal femoral component angle & $94.6^{\circ}\left(88.5^{\circ}\right.$ to $\left.101^{\circ}\right)$ & $95.9^{\circ}\left(90.9^{\circ}\right.$ to $\left.98.9^{\circ}\right)$ & $89.8^{\circ}\left(84.2^{\circ}\right.$ to $\left.95.5^{\circ}\right)$ \\
Coronal tibial component angle & $89.7^{\circ}\left(84.7^{\circ}\right.$ to $\left.95.8^{\circ}\right)$ & $85.1^{\circ}\left(78.0^{\circ}\right.$ to $\left.95.9^{\circ}\right)$ & 0.7264 \\
Sagittal femoral component angle & $84.7^{\circ}\left(75.0^{\circ}\right.$ to $\left.93.5^{\circ}\right)$ & $86.5^{\circ}\left(79.0^{\circ}\right.$ to $\left.94.0^{\circ}\right)$ & 0.5223 \\
Sagittal tibial component angle & $86.6^{\circ}\left(80.0^{\circ}\right.$ to $\left.95.6^{\circ}\right)$ & & 0.7059 \\
\hline
\end{tabular}

Data are presented as mean measurement (range).

differences in the 2 sagittal alignment measurements were also not statistically significant $(P=0.5223$ and $P=0.7059$, respectively).

\section{DISCUSSION}

Our data show that overall alignment in TKA does not appear to be affected by obesity as we found no statistically significant relationship between obesity and TKA coronal and sagittal alignment measurements. This finding is important as obesity is generally recognized to be associated with worse outcomes, as well as increased morbidity and mortality, in TKA.

Merle-Vincent et al presented data on a series of 264 patients in a prospective multicenter study that sought to identify factors predicting patient satisfaction 2 years after TKA for osteoarthritis. ${ }^{5}$ Factors significantly associated with good satisfaction in the multivariate model included age $>70$ years, severe joint space narrowing, absence of depression at the 2-year evaluation, and a BMI $<27 \mathrm{~kg} / \mathrm{m}^{2}$.

Järvenpää et al presented data on a series of 100 patients in a prospective study that looked at the short-term outcome of obese $\left(B M I \geq 30 \mathrm{~kg} / \mathrm{m}^{2}\right.$ ) and nonobese $\left(B M l<30 \mathrm{~kg} / \mathrm{m}^{2}\right.$ ) TKA patients using clinical, functional, and radiologic analysis. ${ }^{21}$ They noted a higher rate of complications, worse postoperative range of motion, and an increased number of technical errors in the obese group and concluded that obesity may impair early outcomes of TKA and that obese patients should be educated regarding the increased complications.

As noted earlier, many factors influence the outcome of TKA including patient-related factors, ${ }^{5,6}$ prosthesis-related factors, ${ }^{7}$ and surgical technique-related factors. ${ }^{8}$ As we did not find that obesity had a significant effect on mechan- ical alignment in TKA, another factor may be associated with worsened outcomes in obese patients. Further investigation is necessary to determine why these individuals appear to have worse outcomes after TKA.

One limitation of this study is that all 3 surgeons used different arthroplasty devices. Use of the different guides made for the three devices may be a confounding factor. Also, during the study period, a higher proportion of obese subjects had TKA compared to nonobese subjects. This difference may be related to both the pathoanatomy of degenerative joint disease and the patient population of the study center. Finally, the difference in age in the obese group compared to the nonobese group (average age 63.9 vs 71.4 years) may be a confounding factor secondary to decreased bone quality with advanced age and is a factor to be further investigated. The strengths of this study include the number of patients included in the analysis and the reproducibility of the radiographic parameters.

\section{CONCLUSION}

In our study, we found no relationship between obesity and TKA component alignment. This finding suggests that mechanically, arthroplasty can be performed at the same level of accuracy and precision in obese patients as in nonobese patients. Because obesity is negatively associated with patient outcome following TKA, another variable other than component position may be the causal factor.

\section{ACKNOWLEDGMENTS}

Dr George Chimento is a consultant for Stryker Corporation. Otherwise, the authors have no financial or proprietary interest in the subject matter of this article. 


\section{REFERENCES}

1. Rodricks DJ, Patil S, Pulido P, Colwell CW Jr. Press-fit condylar design total knee arthroplasty. Fourteen to seventeen-year follow-up. J Bone Joint Surg Am. 2007 Jan;89(1):89-95.

2. Vessely MB, Whaley AL, Harmsen WS, Schleck CD, Berry DJ. The Chitranjan Ranawat Award: long-term survivorship and failure modes of 1000 cemented condylar total knee anthroplasties. Clin Orthop Relat Res. 2006 Nov;452:28-34.

3. Ito J, Koshino T, Okamoto R, Saito T. 15-year follow-up study of total knee arthroplasty in patients with rheumatoid arthritis. J Arthroplasty. 2003 Dec;18(8):984-992.

4. Ranawat CS, Flynn WF Jr, Saddler S, Hansraj KK, Maynard MJ. Long-term results of the total condylar knee arthroplasty. A 15year survivorship study. Clin Orthop Relat Res. 1993 Jan; (286):94-102.

5. Merle-Vincent F, Couris CM, Schott AM, et al; Osteoarthritis Section of the French Society for Rheumatology. Factors predicting patient satisfaction 2 years after total knee arthroplasty for osteoarthritis. Joint Bone Spine. 2011 Jul;78 (4):383-386. doi: 10.1016/j.jbspin.2010.11.013.

6. Anderson L, Kammerer WS, Greer RB 3rd. Risk factor assessment in 101 total hip arthroplasties: a medical perspective. Clin Orthop Relat Res. 1979 Jun;(141):50-54.

7. Griffin WL, Fehring TK, Pomeroy DL, Gruen TA, Murphy JA. Sterilization and wear-related failure in first- and secondgeneration press-fit condylar total knee arthroplasty. Clin Orthop Relat Res. 2007 Nov;464:16-20.

8. Berger RA, Crossett LS, Jacobs JJ, Rubash HE. Malrotation causing patellofemoral complications after total knee arthroplasty. Clin Orthop Relat Res. 1998 Nov;(356):144-153.

9. Pi-Sunyer FX. The medical risks of obesity. Obes Surg. 2002 Apr;12 Suppl 1:6S-11S.

10. Abdullah A, Wolfe R, Stoelwinder JU, et al. The number of years lived with obesity and the risk of all-cause and cause-specific mortality. Int J Epidemiol. 2011 Aug;40(4):985-996. doi: 10.1093/ ije/dyr018.

11. Kulie T, Slattengren A, Redmer J, Counts H, Eglash A, Schrager S. Obesity and women's health: an evidence-based review. J Am Board Fam Med. 2011 Jan-Feb;24(1):75-85. doi: 10.3122/ jabfm.2011.01.100076.

12. Deshmukh RG, Hayes JH, Pinder IM. Does body weight influence outcome after total knee arthroplasty? A 1-year analysis. J Arthroplasty. 2002 Apr;17(3):315-319.
13. Foran JR, Mont MA, Etienne G, Jones LC, Hungerford DS. The outcome of total knee arthroplasty in obese patients. $J$ Bone Joint Surg Am. 2004 Aug;86-A(8):1609-1615.

14. Chesney D, Sales J, Elton R, Brenkel IJ. Infection after knee arthroplasty a prospective study of 1509 cases. J Arthroplasty. 2008 Apr;23(3):355-359. doi: 10.1016/j.arth.2007.05.052.

15. Rajgopal V, Bourne RB, Chesworth BM, MacDonald SJ, McCalden RW, Rorabeck $\mathrm{CH}$. The impact of morbid obesity on patient outcomes after total knee arthroplasty. J Arthroplasty. 2008 Sep:23(6):795-800. doi: 10.1016/j.arth.2007.08.005.

16. Namba RS, Paxton L, Fithian DC, Stone ML. Obesity and perioperative morbidity in total hip and total knee arthroplasty patients. J Arthroplasty. 2005 Oct;20(7 Suppl 3):46-50.

17. Spicer DD, Pomeroy DL, Badenhausen WE, et al. Body mass index as a predictor of outcome in total knee replacement. Int Orthop. 2001;25(4):246-249.

18. Foran JR, Mont MA, Rajadhyaksha AD, Jones LC, Etienne G, Hungerford DS. Total knee arthroplasty in obese patients: a comparison with a matched control group. J Arthroplasty. 2004 Oct;19(7):817-824.

19. Amin AK, Patton JT, Cook RE, Brenkel IJ. Does obesity influence the clinical outcome at five years following total knee replacement for osteoarthritis? J Bone Joint Surg Br. 2006 Mar;88(3):335-340.

20. Vazquez-Vela Johnson G, Worland RL, Keenan J, Norambuena N. Patient demographics as a predictor of the ten-year survival rate in primary total knee replacement. $J$ Bone Joint Surg Br. 2003 Jan;85(1):52-56.

21. Järvenpää J, Kettunen J, Kröger $H$, Miettinen $H$. Obesity may impair the early outcome of total knee arthroplasty. Scand J Surg. 2010;99(1):45-49.

22. Perka C, Tohtz S, Matziolis G. Axial correction in knee revision arthroplasty [in German]. Orthopade. 2006 Feb;35(2):136-142.

23. Rand JA, Coventry MB. Ten-year evaluation of geometric total knee arthroplasty. Clin Orthop Relat Res. 1988 Jul;(232):168-173.

24. McPherson EJ, Cuckler J, Lombardi AV. Midflexion instability in revision total knee arthroplasty. Surg Technol Int. 2008;17:249252.

25. Berend ME, Davis PJ, Ritter MA, et al. "Thicker" polyethylene bearings are associated with higher failure rates in primary total knee arthroplasty. J Arthroplasty. 2010 Sep;25(6 Suppl):1720. doi: 10.1016/j.arth.2010.04.031.

This article meets the Accreditation Council for Graduate Medical Education and the American Board of Medical Specialties Maintenance of Certification competencies for Patient Care and Medical Knowledge. 